\title{
CCLXVI. THE SYNTHESIS OF AMINO-ACIDS.
}

\section{TRYPTOPHAN.}

\author{
BY WILLIAM JOHN BOYD AND WILLIAM ROBSON. \\ From the Department of Physiology, University of London, King's College.
}

(Received July 25th, 1935.)

TRYPTOPHAN was first synthesised by Ellinger and Flamand [1907] by the classical Erlenmeyer method. The yield of the amino-acid was however only $15-20 \%$ of the theoretical amount obtainable from the indole-3-aldehyde employed. Using the identical procedure, Ellinger and Matsuoka [1914] and Barger and Ewins [1917] prepared 2-methyltryptophan from 2-methylindole-3-aldehyde. In both these cases, as in that of tryptophan itself, the final product had to be purified by precipitation with mercuric sulphate. Barger and Ewins obtained over $40 \%$ of the theoretical amount calculated on the aldehyde.

Majima and Kotake [1922], on the other hand, synthesised tryptophan by condensing indole-3-aldehyde with hydantoin by heating these substances together in the presence of acetic anhydride and sodium acetate, reducing the product with sodium amalgam and hydrolysing the saturated hydantoin with strong aqueous barium hydroxide. These workers also used the mercuric sulphate precipitation for the isolation of the amino-acid. Robson [1924] prepared 5 -methyltryptophan by a method similar to that of Majima and Kotake, but omitted the mercuric sulphate precipitation. The yield however was very low. This synthesis has recently been repeated by Gordon and Jackson [1935] but no better results are reported.

On attempting in this laboratory to repeat the results obtained by Ellinger and Flamand, great difficulty has invariably been experienced at the reduction stage of the synthesis both of tryptophan and of its homologues. The product of the reaction was always an amorphous precipitate which resisted all attempts at crystallisation. Moreover, hydrolysis of the product failed to yield appreciable amounts of the amino-acid, although the final solutions gave the typical colour reactions of tryptophan in moderate degree. Similar trouble was experienced with Majima and Kotake's method more particularly when applied to the synthesis of 5-methyltryptophan [Robson, 1924].

In looking for a possible explanation of the difficulty, it appeared highly probable, since indole is itself so easily hydrogenated by much the same means as has been used for the reduction of these benzamidoacrylic acids, that there was present in the reduction product not only benzoyltryptophan together with some unchanged $\alpha$-benzamido- $\beta$-indolylacrylic acid but also the corresponding dihydroindole compound. Such a mixture might be expected to be difficult to crystallise.

Such reasoning led to the quest for another mode of reducing the double bond of the side-chain without affecting the nucleus. It has been shown by the authors $[1935,2]$ that in the reduction stage of the hydantoin synthesis of aromatic amino-acids, sodium amalgam can be satisfactorily replaced by ammonium sulphide, and that excellent yields of phenylalanine, methoxyphenylalanine and tyrosine can be obtained in this way. 
On applying this modification to the synthesis of tryptophan an unforeseen difficulty appeared in the insolubility of indolalhydantoin in the various solvents used so successfully for the preparation of benzylhydantoin and phenylalanine. The rate of reduction of indolalhydantoin is slower than that of benzalhydantoin even in aqueous ammonium sulphide and scarcely proceeds at all at $100^{\circ}$ in non-aqueous hydrogen sulphide solutions even when the indolalhydantoin is all in solution. This accentuates the difficulty arising from the insolubility.

Moreover, owing to the insolubility of indolylhydantoin it is difficult to free it from the last traces of indolalhydantoin. For these reasons the attempt to prepare indolylhydantoin directly in good yield and purity has not been successful. The search for a suitable solvent has greatly delayed the publication of this work. These difficulties have been surmounted, however, by combining the reduction and the hydrolysis in one operation involving heating of the indolalhydantoin with ammonium sulphide-ammonium hydroxide solution for 500 hours at $100-105^{\circ}$, whereby a $50-60 \%$ theoretical yield of colourless, analytically pure tryptophan is obtained from such small quantities as $2-3 \mathrm{~g}$. of indolalhydantoin without the necessity of a mercuric sulphate precipitation or even of a recrystallisation. A second crop of slightly less pure amino-acid brings the yield up to $70 \%$ of the amount theoretically obtainable from the indolalhydantoin. By carrying out the reaction at a higher temperature, the time can be considerably shortened but the practical difficulties attendant on such a procedure render the lower temperature preferable.

It may be added that the solubility difficulty is not so great in the preparation of 7-methyltryptophan which will be described in a later paper.

Finally, the piperidine method of preparing indolalhydantoin has considerable advantages over the acetic anhydride-sodium acetate method as shown by the better yield and purity of the product obtained ( $c f$. Boyd and Robson $[1935,1])$.

\section{EXPERIMENTAL.}

Indole-3-aldehyde. The preparation of this substance with improved yields has already been described [Boyd and Robson, 1935, 3].

Indolalhydantoin. Indole-3-aldehyde (6.5 g.), hydantoin (5.4 g. or 1.2 mols.) and piperidine $(20 \mathrm{ml}$.) were heated together under a reflux condenser for $30 \mathrm{~min}$. After 15-20 min. the highly coloured solution began to deposit a yellow crystalline precipitate of indolalhydantoin piperidine salt. The mixture was poured into a large bulk of water and acidified with acetic acid. The precipitate was collected, washed with methyl alcohol to remove any unchanged aldehyde and some colouring matter and finally recrystallised from glacial acetic acid. Yield $6.6 \mathrm{~g}$. or $65 \%$ of the theoretical. It melted at $330^{\circ}$. (Majima and Kotake found $325^{\circ}$ ) and contained $18.29 \% \mathrm{~N}$. $\mathrm{C}_{12} \mathrm{H}_{9} \mathrm{O}_{2} \mathrm{~N}_{3}$ requires $18.50 \% \mathrm{~N}$.

Tryptophan. Indolalhydantoin (2.5 g.), $16 \%$ ammonium sulphide (50 ml.) and $3 \%$ ammonium hydroxide $\left(20 \mathrm{ml}\right.$.) were heated in a closed vessel at $100-103^{\circ}$ for 500 hours. At the end of that time $0.24 \mathrm{~g}$. of unchanged indolalhydantoin (M.P. $327^{\circ}$ ) was filtered off. The filtrate was evaporated to dryness in vacuo and the residue extracted repeatedly by boiling it with fresh quantities of water containing a little ammonia, the total volume amounting to about $700 \mathrm{ml}$. The insoluble residue was treated with a little carbon disulphide to remove sulphur and the mixture filtered. The insoluble residue was again boiled out with ammoniacal water and the suspension filtered. The filtrate was added to the previous extract. The combined ammoniacal extracts were concentrated to $400 \mathrm{ml}$., boiled with a little animal charcoal, filtered and concentrated to $100 \mathrm{ml}$. 
Alcohol (400 ml.) was added to the concentrate and the solution set aside. The amino-acid which crystallised out slowly was filtered off, washed with $80 \%$ alcohol and dried. It weighed $0.98 \mathrm{~g}$., melted at $275-282^{\circ}$, and contained $13.76 \% \mathrm{~N}$ (micro-Kjeldahl). $\mathrm{C}_{11} \mathrm{H}_{12} \mathrm{O}_{2} \mathrm{~N}_{2}$ requires $13 \cdot 72 \% \mathrm{~N}$.

A further crop of $0.45 \mathrm{~g}$. of slightly less pure product was obtained by concentrating the mother liquor to $10-20 \mathrm{ml}$. and adding $100 \mathrm{ml}$. of alcohol. The total amount of tryptophan isolated was $70 \%$ of the theoretical figure, but further amounts of very impure amino-acid were obtained together with a little impure indolylhydantoin.

The 3:5-dinitrobenzoyl derivative melted at $240^{\circ}$, after preliminary softening at about $230^{\circ}$. The 3:5-dinitrobenzoyl derivative prepared from a sample of $l$-tryptophan isolated from caseinogen softened and melted at the same temperatures as the derivative of the synthetic amino-acid. A mixed melting-point likewise gave $240^{\circ}$ (Saunders [1934] gives $233^{\circ}$ ).

A second experiment was carried out wherein indolalhydantoin $(2 \cdot 3 \mathrm{~g}$.) was heated in a sealed tube with ammonium sulphide $(8 \mathrm{ml}$.) and alcohol $(4 \mathrm{ml}$.) for 5 hours at a temperature ranging from 150 to $175^{\circ}$. The product was worked up as described above, the amino-acid being finally crystallised from $60 \%$ alcohol. The total yield was only $0.4 \mathrm{~g}$., and it melted at $275-287^{\circ}$.

\section{SUMmary.}

By using piperidine as catalyst for the condensation of indole-3-aldehyde with hydantoin and ammonium sulphide as the reducing and hydrolytic reagent, tryptophan can be prepared without difficulty in good yield and purity. The method, which does not involve the usual precipitation with mercuric sulphate, is readily applicable to the preparation of small quantities of the amino-acid.

\section{REFERENCES.}

Barger and Ewins (1917). Biochem. J. 11, 58.

Boyd and Robson (1935, 1). Biochem. J. 29, 542.

$-(1935,2)$. Biochem. J. 29, 546.

- - (1935, 3). Biochem. J. 29, 555.

Ellinger and Flamand (1907). Z. physiol. Chem. 55, 8.

— and Matsuoka (1914). Z. physiol. Chem. 91, 50.

Gordon and Jackson (1935). J. Biol. Chem. 110, 151.

Majima and Kotake (1922). Ber. deutsch. chem. Ges. 55, 3859.

-Robson (1924). J. Biol. Chem. 62, 495.

Saunders (1934). Biochem. J. 28, 580 . 